\title{
DISEÑOS DEL SIGLO XIX PARA UN INVERNADERO EN LA «CASA DE LA REINA»
}

\author{
POR \\ EVA J. RODRÍGUEZ ROMERO \\ CEU-Arquitectura (U.P.M.)
}

\begin{abstract}
$19^{\text {th }}$ century desings for a «Queen's House» rooftop glasshouse, in Costanilla de los Ángeles street of Madrid, are studied. There are drawings representing elegant greenhouses to make the building top. These projects were accomplished by the French architect P. Quénat, because in Spain the rooftop greenhouses were not very abundant. This causes that said projects will be more interesting. We comment the greenhouses paper at the Spanish $19^{\text {th }}$ century society, the most abundant types and the most famous examples, to locate these drawings in their context.
\end{abstract}

En los jardines y parques del siglo xIX uno de los elementos más característicos fueron los invernaderos o estufas, como era habitual designarlos entonces, que contenían las especies exóticas. Muchas veces estas delicadas construcciones no eran totalmente exentas, sino que tenían una íntima relación con la casa. Se solían adosar a las fachadas posteriores o laterales como transición etérea entre la arquitectura y el jardín, como fue corriente en las villas suburbanas e, incluso, en los palacetes que la nobleza y la «aristocracia del dinero» levantaba en las nuevas calles de las ciudades en expansión. Las estufas unían belleza y utilidad, eran un signo de distinción y siempre representaron una arquitectura de vanguardia que aprovechaba las ventajas de las nuevas técnicas ${ }^{1}$. Llegaron a realizarse diseños prefabricados para cerrar balconadas o para las azoteas de los inmuebles de varias plantas. Si el edificio tenía cierta entidad o los propietarios disponían de solvencia económica estas «estufas para el tejado» se diseñaban ex profeso por arquitectos o especialistas en este tipo de construcciones, como es el caso de los dibujos que estudiamos en este artículo. Constituyen el conjunto de proyectos realizados hacia 1878 para instalar un invernadero a modo de remate de la llamada «Casa de la Reina», en la Costanilla de los Ángeles de Madrid.

\footnotetext{
${ }^{1}$ Cfr. Hix, John: The Glasshouse, ed. Phaidon, 1996 (1. ${ }^{a}$ ed. 1974), p. 8. Las grandes estufas del siglo xix debían su forma no a los principios del diseño arquitectónico tradicional sino a la experimentación de los jardineros sobre los problemas de calefacción, ventilación, luz y sombra que necesitaban las plantas, flores y frutos para desarrollarse y conservarse. Se aplicaban en ellas los nuevos materiales ingenieriles aunque los motivos ornamentales de las mismas sí seguían la corriente de los neos y el eclecticismo característico decimonónico.
} 


\section{El papel de los invernaderos en la arquitectura del siglo XIX}

Desde el siglo xvir la botánica había tenido su gran auge y durante el siglo xix ese interés se extendió más allá de los límites puramente científicos y económicos, buscándose plantas extrañas fundamentalmente con un sentido de lucimiento dentro del arte del jardín pintores$\mathrm{co}^{2}$, símbolo de los nuevos tiempos. En el siglo xIX ese interés se tradujo en toda Europa, pues, en una allléntica «furia» por la aclimatación de plantas exóticas con fines ornamentales, costumbre que había comenzado el siglo anterior por parte de los aristócratas ingleses ${ }^{3}$. Por tanto, la aclimatación de vegetales de otras latitudes se vinculó primero a su carácter comestible o utilitario y sólo después a su carácter ornamental. Las plantas eran buscadas por sus aplicaciones medicinales, como alimentos, especias y conservantes, como textiles, tintóreas, barrilleras... y en último lugar como ornamentales ${ }^{4}$; pero en el siglo xIX, satisfechas ya muchas de las necesidades de la sociedad, la moda de las plantas exóticas tiene un sentido artístico dentro de las composiciones jardineras.

Lógicamente hay una relación entre el desarrollo de la botánica, el nuevo estilo de jardín y la proliferación de invernaderos y estufas. Se crearon colecciones botánicas, que enlazaban con las tendencias ilustradas, en los ambientes cultos y aristócratas, contribuyendo asimismo a la difusión del jardín pintoresco, que nació también en relación con las corrientes fisiócratas. Las nuevas especies vegetales disponibles con fines ornamentales, como araucarias, ficus, magnolios, etc., tienen una envergadura y un porte muy distinto del de las moreras, naranjos, limoneros y cipreses, por lo que también generarán nuevas formas en el diseño del jardín ${ }^{5}$, en una relación biunívoca. Además, en el siglo XIX, el arte del jardín se convierte en el arte de las técnicas de horticultura con la corriente gardenesque y la sensibilidad romántica, con su culto por la Naturaleza, despierta el interés por los jardines curiosos y útiles como los del jardinero inglés Repton.

En los siglos XVIII y XIX se organizaron las expediciones científicas más relevantes y se creó todo un sistema de comercio e intercambio de especies vegetales entre América y diversos países europeos ${ }^{6}$. En verdadera comunión con estas grandes empresas científicas debemos re-

\footnotetext{
${ }^{2}$ De todas formas, no era una costumbre totalmente nueva. Hasta el descubrimiento de América los jardines principales estaban en la cuenca del Mediterráneo y se componían con plantas autóctonas, más las plantas orientales que romanos y árabes aclimataron en tiempos remotos. Desde el siglo xvı al siglo xix la aportación española primero, y de otros países después a la nueva flora, con el descubrimiento de nuevas especies, generó modas o incluso locuras sociales, como lo sucedido con los tulipanes o las orquídeas. A partir del siglo xix se introdujeron en Europa los descubrimientos botánicos que abarcaban Asia, África y Oceanía. Estas tres etapas las establece Francisco Páez de la Cadena: Historia de los Estilos en Jardinería, Istmo, Madrid, 1982, p. 159

3 Antonio Ponz resume magistralmente las razones por las que «coleccionar» plantas exóticas, al igual que cualquier otra maravilla, se convirtió en una verdadera pasión de la sociedad acomodada: «Cada uno de estos señores tiene su particular afición en sus casas de campo; quién a las artes, quién a perfeccionar y aumentar el cultivo de las plantas y flores. En ellas suelen tener excelentes bibliotecas, monetarios y otras curiosidades. Pasan en ellas gran parte del año, particularmente en las vacaciones del Parlamento. Las perfeccionan, extienden y hermosean con emulación y competencia. Dueños de grandes riquezas, que la industria y el comercio ha traído a este reino, han procurado fijarlas en este modo, comprando en todas partes adonde llega su vastísima navegación cuanto ha podido haber de exquisito y estimable» (A. Ponz: Viaje fuera de España, Ed. Aguilar, Madrid, 1988, p. 209.) Esta costumbre se extendió después en la naciente burguesía.

${ }^{4}$ Cfr. Steele, Arthur R.: Flores para el rey. La expedición de Ruiz y Pavón y la Flora del Perú (1777-1788), Ed. del

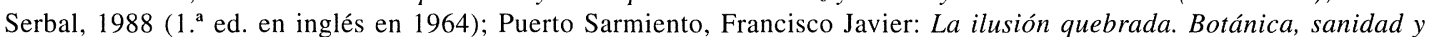
política científica en la España Ilustrada, C.S.I.C., Serbal, 1988 y «Botánica, Medicina, Terapéutica y Jardines Botánicos», en VV.AA.: Carlos III y la Ilustración, Lunwerg editores, Madrid, 1988, pp. 295-306; González Bueno, Antonio: «La aclimatación de plantas americanas en los jardines peninsulares», en Fernández Pérez, Joaquín y González Tascón, Ignacio (eds.): La agricultura viajera. Cultivos y manufacturas de plantas industriales y alimentarias en España y en la América Virreinal, C.S.I.C., Madrid, 1990. pp. 37-52.

${ }^{5}$ Sobre las especies vegetales que se cultivan a lo largo de los siglos en los jardines y su relación con el diseño de los mismos ver Hobhouse, Penelope: Plants in Garden History, Pavilion, Londres, 1994 ( $1^{\mathrm{a}}$ ed. 1992).

${ }^{6}$ Los objetivos prioritarios de las expediciones fueron la astronomía y la botánica. El perfeccionamiento de la astronomía era capital para la navegación y, en el campo de la política territorial, para la fijación de fronteras; la botánica era fun-
} 
cordar la existencia de los jardines botánicos, donde se coleccionan plantas de manera que se mantengan vivas y aptas para su estudio. Madrid tuvo su primera colección de plantas ya en tiempos de Felipe V, en Migas Calientes, en el camino de El Pardo a orillas del Manzanares, creada por el boticario de cámara Riqueur. Con Fernando VI, en 1755, se formó el primer Jardín Botánico verdadero, también en Migas Calientes. En 1778 se empezaron a trasladar las plantas al Real Jardín Botánico del Prado, que bajo la protección de Carlos III sería uno de los más célebres de Europa, comenzando a funcionar en 1781. Así, los jardines botánicos de España, aparte de ser instituciones de enseñanza de las disciplinas científicas, se crearon fundamentalmente para traer y aclimatar las plantas exóticas de las colonias de ultramar. A tal fin se estableció toda una red de jardines accesorios en Cádiz, Algeciras, Córdoba, Málaga, Cartagena, Tenerife, etc., para aclimatar paulatinamente las plantas que después adornaban los Parques Reales de Aranjuez ${ }^{7}$, La Granja, el Retiro... y su actividad era coordinada desde Madrid por un sistema de corresponsalías. Está claro que la implantación en los jardines reales de especies botánicas de las Colonias era una forma de propaganda a favor de la Corona, tanto por su vasto dominio como por su fomento de las ciencias. También en algunos jardines de la nobleza se cultivaron plantas exóticas en el siglo xviII, como en la Alameda de Osuna, donde compraban árboles, arbustos y flores a los viveros de Aranjuez, el Retiro, San Fernando y traían otros desde Francia ${ }^{8}$.

Según el jardinero Pablo Boutelou, como España se halla equidistante de los países más fríos y de los más cálidos del globo y tiene además una variedad de climas diferentes entre sí, es perfecto para la connaturalización de muchas plantas exóticas ${ }^{9}$, pero sin embargo no fue uno de los que más empeño pusieron en tal labor. Así, Inglaterra y Francia, menos favorables climáticamente, dedicaron mayores esfuerzos a la aclimatación de especies exóticas. Para conseguir una total naturalización y aclimatación era necesario ir acostumbrando lentamente a los vegetales a una serie graduada de climas. Por ello, los que provenían de América del Sur o África eran llevados primero a Canarias, para enviarlos luego a puntos abrigados de Levante y de allí a Sevilla, Murcia y Extremadura, antes de llegar al Botánico de Madrid o los jardines de los Sitios Reales, desde donde, si era posible, se difundían al resto del reino y a otros países.

Para el desarrollo de todas estas especies exóticas se necesitan muchas veces refugios especiales como paso previo a su crecimiento al aire libre, incluso en países como España, sobre

\footnotetext{
damental para inventariar el mundo vegetal de cara a evaluar el interés farmacológico, medicinal, agrícola, industrial u ornamental que tenía cada especie, así como la rentabilidad que suponía su comercialización. Sobre estas expediciones ver, aparte de las obras ya citadas de Steele y Puerto Sarmiento, por ejemplo: Colmeiro, Miguel: Primeras noticias acerca de la vegetación americana. Con un resumen de las expediciones botánicas de los españoles, Ateneo de Madrid, 1892; Arias Divito, Juan Carlos: Las Expediciones Científicas Españolas durante el siglo xvIII, Ed. Cultura Hispánica, Madrid, 1968; Calatayud Arinero, $\mathrm{M}^{\mathrm{a}}$ Ángeles: Catálogo de la expediciones y viajes científicos españoles, siglos xVIII y XIX. C.S.I.C., Madrid, 1984. VV.AA.: La expedición botánica al virreinato del Perú (1777-1788), Lunwerg, Madrid, 1988; Peset, José Luis: «Ciencia y técnica: las expediciones científicas», en Carlos III y la Ilustración, Lunwerg, Madrid, 1988, pp. 285-294; VV.AA.: La botánica en la expedición Malaspina, 1789-1794, Turner, Madrid, 1989; Campo, M. ${ }^{\mathrm{a}}$ Isabel del: Sobre la introducción de plantas americanas en España. Ministerio de Agricultura, Madrid, 1993 y el número monográfico de la revista Asclepio, vol. XLVII-2, 1995.

${ }^{7}$ El encargado de cuidar el jardín de aclimatación, que se encontraba en el Jardín del Príncipe de Aranjuez, era Esteban Boutelou, que aunque habla del fin ornamental de las plantas para los jardines reales reconoce que «Son utilísimas las colecciones de plantas raras que en los jardines botánicos se cultivan para la instrucción pública y la grandeza del Soberano; pero son unos verdaderos manantiales de prosperidad siempre que se logre... algún vegetal ó árbol útil á las artes ó en la economia doméstica, á lo qual deben dirigirse principalmente las ideas de semejantes establecimientos.» (Esteban Boutelou: «Noticia de algunos árboles exóticos cultivados en Aranjuez», Semanario de Agricultura y Artes, n. ${ }^{\circ}$ 9, 1801, p. 234 , nota 62 ).

${ }^{8}$ El botánico Lagasca dice de la duquesa de Osuna que «tiene más espíritu y gusto en botánica y jardinería que todos los demás Grandes de España juntos» y que su Alameda «se embellece con fuentes, bassins, cascadas, túneles, estatuas, templos, etc. y está bien provista de estufas donde se consiguen muchas curiosas plantas exóticas» (M. la Gasca: «On the Gardening and Botany of Spain», The Gardener's Magazine, junio 1828, p. 70).

9 Pablo Boutelou: Memoria acerca de la aclimatación de las plantas ecsóticas (sic) por..., Sevilla, 1842, p. 11.
} 
todo en las zonas interiores de clima continental. Una vez que las plantas han sido aclimatadas pueden crecer y fructificar en el exterior. Inglaterra tiene un clima que favorece el desarrollo de la gran vegetación y la frescura del césped, pero muchas de las plantas que se cultivan al aire libre en Francia o en España requieren de invernaderos o estufas. Ello explica el papel tan importante que adquirieron allí estos edificios, llegando a haber incluso «Jardines de Invierno» interiores, en comparación con el que desempeñan en nuestro país. Aún así, aquí también existieron desde el siglo XVI, y sobre todo en el siglo xIX, importantes invernaderos que apenas han sido estudiados.

\section{Tipologías de invernaderos y los ejemplos españoles}

Los invernáculos existían desde antiguo como lugar de retiro invernal para las plantas más delicadas, como las orangeries para cítricos inventadas por Roma y difundidas en las villas renacentistas en su habitual tipología: pequeños edificios de fábrica con anchos ventanales en el frente. En el siglo XVIII parecían elegantes templetes como el famoso invernadero Galilei de Richard Bradley en 1718. Muy novedosa fue la temprana estufa acristalada de la Malmaison (1803-1805), donde el botánico particular de Josefina, Etienne Ventenant, cuidaba de especies raras de Egipto, Australia y América del Norte, que eran dibujadas por el artista botánico Pierre Joseph Redouté ${ }^{10}$, sirviendo de antecedente a las grandes estufas acristaladas de mediados del XIx. Así pues, la estufa caliente fue una invención del siglo xIX, cuando la hicieron posible ciertas técnicas especiales de ventilación y calefacción ${ }^{11}$. Una de las más bellas del mundo es la Casa de las Palmeras de Richard Turner en los jardines de Kew ${ }^{12}$, construida entre 1845 y 1848 , en fundición, hierro forjado y cristal, que supuso la instauración de un tipo que sería repetido e imitado en invernaderos como la Casa de las Palmeras de Schönbrunn o la Estufa de Laeken en Bruselas (1886), por ejemplo. El gran tecnólogo de las estufas fue el jardinero inglés John Claudius Loudon ${ }^{13}$, pero el ejemplo más conocido de estos edificios es el Crystal Palace de Joseph Paxton, construido en 1851 para la Exposición Universal de Londres, que siguiendo la moda de los «Jardines de Invierno» públicos ${ }^{14}$ fue fundamental para la acepta-

\footnotetext{
${ }^{10}$ Penelope Hobhouse: Plants in Garden History, op. cit., pp. 219-220.

$"$ Sobre la historia de los invernaderos y la evolución de las distintas tipologías se puede consultar: Kohlmaier, Georg y Sartory, Barna von: Houses of Glass: a Nineteenth-Century Building Type, MIT Press, Cambridge, 1986; Woods, May y Warren, Arete: Glass Houses, Aurum Press, Singapur, 1988; y Hix, John: The Glasshouse, op. cit.

12 Ver Kultermann, Udo: «La Casa de las Palmeras de Richard Turner en los jardines de Kew», Goya, n. ${ }^{\circ}$ 211-212, 1989, pp. 73-77 y Minter, Sue: The Greatest Glass House, Royal Botanic Garden of Kew, Londres, 1990.

${ }_{13}$ Renzo Dubbini: «Serres et jardins d'hiver», en MOSSER, Monique y Teyssot, Georges (eds.): Histoire des jardins de la Renaissance à nos jours, Ed. Flammarion, Paris, 1991, pp. 423-425. Loudon escribió entre sus numerosas aportaciones a la jardinería Remarks on the Construction of Hothouses (1817), aunque su obra más conocida es la Encyclopaedia of Gardening. Fue el primero en estudiar la disposición correcta de las vidrieras teniendo en cuenta la inclinación variable de los rayos del sol durante el día, según las estaciones y las diferentes latitudes.

${ }^{14}$ El primer Jardín de Invierno fue el de Berlín (1814), al que siguieron los de Estrasburgo y Viena, pero eran todavía edificios donde predominaban los elementos de fábrica. Turner y Burton, ya en 1840, construyen el Jardin de Invierno de Regent's Park que sentó el modelo de numerosas estufas, de planta rectangular, con la parte central más elevada y una tribuna para ver las plantas desde arriba. Fue muy conocido también el Jardin d'Hiver de París de Hector Horeau. En España no se llegó a construir ninguna de estas inmensas estructuras, aunque sí que hubo invernaderos públicos más modestos y varios intentos para levantar algún Jardín de Invierno. Así, en 1860 se proyectó uno para los Campos Elíseos de Madrid, en hierro y cristal, y Enrique Repullés y Vargas, siendo aún estudiante en 1868, diseñó un mercado de pájaros y flores para la Plaza de Santa Ana, con un invernadero para plantas tropicales, con un estanque para aves acuáticas y peces, dos pajareras... y un jardín de recreo en el resto de la plaza (Carmen Ariza: «Proyectos no realizados en los jardines madrileños decimonónicos», Anales del Insto. de Estudios madrileños, 1986, pp. 87-97) En 1876 se celebró un concurso para el Buen Retiro, al cual Robert Morham, de Edimburgo, presentó un edificio-salón en hierro y cristal a modo de jardín de invierno (A.S.A., leg. 6-35-3-61. Citado por Carmen Ariza: «Proyectos no realizados en el Retiro durante el siglo XIX», Villa de Madrid, $\mathrm{n}^{\circ} 93,1987$, pp. 25-46).
} 
ción por parte del público de la nueva arquitectura de hierro y cristal. Se levantó en medio de Hyde Park (luego fue trasladado y finalmente pereció víctima de un incendio), con estructura metálica vista y piezas de unión de madera al exterior para soportar mejor los cambios de temperatura y la resistencia a la intemperie. Fue el primer gran edificio industrializado de la historia, a base de cerchas y arcos triangulados de hierro forjado sobre columnas de fundición. Así, a partir de la mediados del siglo xix las estufas se convirtieron en el objeto de admiración por excelencia de los grandes jardines botánicos, los parques públicos y las exposiciones de horticultura; los jardineros más famosos del paisajismo y los arquitectos del momento, como Brown, Nash, Repton..., diseñan invernaderos basados en los nuevos materiales pero cuyas formas y decoración siguen siendo reflejo del historicismo o del eclecticismo.

En España hubo invernáculos y estufas en Aranjuez desde el siglo XVII o incluso antes, seguramente del tipo orangerie. En 1754 había un invernadero para flores en el Jardín de la Reina, que se repara en 1778 para aclimatar allí plantas exóticas y en 1765 se instaló otro en la Huerta de la Primavera ${ }^{15}$. Ya en el siglo XIX se construyó un gran «reservatorio» de cristales, con mantillos y estufas para plantas exóticas y para adelantar la fructificación de las «naturales», de manera que la mesa real estuviese servida todo el año con fresas, uvas, higos, judías, etc. ${ }^{16}$. Pero el «boom» de las estufas se dio, como en los otros países, durante el siglo xIx, cuando todo jardín real o de la nobleza no podía carecer de alguno de estos edificios ya fuese para plantas ornamentales o para cultivos productivos. Así, se construyeron estufas en varios Reales Sitios como La Granja, la Casa de Campo, el Retiro, la Florida, el Campo del Moro ${ }^{17}$, la orangerie del Casino de la Reina, varios invernaderos en la Posesión Real de Vista Alegre ${ }^{18}$ y también las estufas de la Alameda de Osuna, la del Palacio de Montijo que era de estilo neomudéjar en hierro y cristal, la del marqués de Salamanca en Recoletos ${ }^{19}$, etc. A mediados de siglo ya eran habituales las estufas en nuestro país y el arquitecto real, Narciso Pascual y Colomer, diseñó en 1844 dos propuestas muy interesantes para los jardines de la Casa de Campo ${ }^{20}$, siguiendo el mismo esquema del Conservatorio de Kassel y de la Estufa Grande de Vista Alegre, con templete central y dos alas rematadas en sendos pabellones. Igualmente, no podían faltar los invernaderos en el Real Jardín Botánico, donde se construyeron en 1856 la Estufa de Graells o de las Palmas, un precioso ejemplo de la arquitectura del hierro, otra estufa de madera para los semilleros y una mayor en 1872 con Colmeiro ${ }^{21}$.

Ya en la segunda mitad del siglo XIX, los invernaderos empezaron a construirse en nues-

15 José Luis Sancho: «El Real Sitio de Aranjuez y el arte del jardín bajo el reinado de Carlos III», Reales Sitios, $\mathrm{n}^{\circ} 98$, 1988, pp. 49-59., pag. 56-57.

16 J.A. Álvarez de Quindós: Descripción histórica del Real Bosque y Casa de Aranjuez, Imprenta Real, Madrid, 1804, p. 303.

17 A.G.P., sec. admva., c ${ }^{a}$ 10.688, exp. 67. Estufas en el Parque de Palacio, la Casa de Campo, Retiro, Florida, Casino, Montaña del Príncipe Pío y Meaques. Entre ellas destacan los diseños para el Parque de Palacio, ya que aparte de la llamada Estufa de las Camelias o Gruta, existente hoy en día, se querían construir una estufa grande para plantas y otra pequeña para ananás. La orden de construirlas se dio en diciembre de 1847 , el plano fue realizado por Narciso Pascual y Colomer con fecha de 24 de abril de 1848 y el 19 de febrero de 1849 se aprobó el proyecto de Nicolás Grouselle y Juan Mitchell para levantarlas.

${ }^{18}$ Cfr. Rodríguez Romero, Eva: El jardín paisajista y las quintas de recreo de los Carabancheles: la Posesión de Vista Alegre, Fundación Universitaria Española, Madrid, 2000, capítulo «Las estufas. La ciencias y el jardín», pp. 329-355.

${ }_{19}$ Esta estufa, construida en Inglaterra por encargo del marqués, fue comprada en 1877 por el Ayuntamiento de Madrid e instalada en el Retiro (A.S.A., leg. 9-166-3). Carmen Ariza: «Los jardines madrileños en el siglo XIX», en VV.AA.: Madrid en la sociedad del siglo xIX, 2 vol., Comunidad Autónoma de Madrid, 1986, pp. 519-537, p. 527. Alrededor de ella se construyó la Rosaleda, pero la estufa desapareció durante la Guerra Civil.

20 A.G.P., plano n. ${ }^{\circ} 1424$ y 1425.

${ }^{21}$ Santiago Castroviejo y Juan Armada: El Jardín Botánico de Madrid, Avapiés y Caja Madrid, 1994, pp. 69-78. La Estufa de Graells se conserva en la actualidad tras varias restauraciones y a su lado se han construido recientemente los modernos invernaderos para plantas tropicales, ecuatoriales y de clima desértico, incorporando los últimos adelantos tecnológicos en este tipo de edificios. 
tros parques públicos. En 1859 se convocó un concurso para levantar un Palacio de Cristal para la Exposición Española ${ }^{22}$ que no llegó a realizarse, pero sí se construiría el conocido Palacio de Cristal del Retiro para la Exposición de Filipinas en 1887. Fue un proyecto de los realizados por Ricardo Velázquez Bosco para este parque y su constructor fue Bernardo Asíns. En su interior se expusieron plantas exóticas procedentes de Filipinas entre fuentes y juegos de agua, recibiendo la luz graduada con toldos al interior. En el parque de la Ciudadela de Barcelona se levantan también edificios para albergar plantas exóticas, como el Umbráculo de Fontsené, de 1883, y el Invernáculo de José Amargós de $1887^{23}$, que afortunadamente, al contrario que el Palacio de Cristal madrileño, conservan en la actualidad su función originaria. También son preciosos el umbráculo y los invernaderos del Jardín Botánico de Valencia.

El tema de los invernaderos fue también abordado en nuestro país en algunos estudios teóricos ${ }^{24}$, como en la obra de Pablo Boutelou, Memoria acerca de la aclimatación de las plantas ecsóticas (sic)... ${ }^{25}$ escrita en 1842. Ya a finales de siglo, Balbino Cortés realiza un estudio exhaustivo de los invernáculos y su construcción en la Novísima guía del hortelano, jardinero y arbolista, donde dedica todo un capítulo a los invernáculos y estufas ${ }^{26}$. Este jardinero explica que, aunque el hierro es más elegante y duradero, la estructura de madera tiene la ventaja de que se calienta y enfría lentamente y no reconcentra tanto el vapor en su interior. Es preciso no olvidar que en el siglo XIX las estufas fueron edificios vanguardistas y experimentos arquitectónicos en conjunción con la experimentación en cultivos y, como tales, emplearon los materiales más novedosos de la época, como la fundición, el hierro forjado y el vidrio templado, que permitieron esas estructuras ligeras y diáfanas tan características. Se tenían en cuenta las diferencias de temperatura, las presiones, la fuerza del viento, la elasticidad y el peso de cada uno de los materiales y elementos... según analogías con la construcción naval, empleando métodos de cálculo pioneros en el campo de las estructuras arquitectónicas. Cuando en 1833 se comenzó a fabricar el vidrio templado, mucho más ventajoso que el tradicional, se pudieron realizar superficies acristaladas mayores y más seguras. Las estufas proliferaron sobre todo a partir de 1845 , cuando estos nuevos materiales bajaron de precio ${ }^{27}$, aunque los invernaderos de este tipo siempre fueron caros de construir y de mantener.

Los modelos y formas de las estufas se multiplicaron, habiendo incluso invernaderos de producción industrial para añadir a las casas, a las terrazas o a los balcones. Además, fue también muy importante el papel que jugaron los invernaderos de cristal en la sociedad de la épo-

${ }^{22}$ A.S.A., leg. 0'59-31-46. Citado por Carmen Ariza: «Proyectos no realizados en los jardines madrileños decimonónicos», Anales del Insto. de Estudios madrileños, 1986, pp. 87-97.

${ }^{23}$ Ver Navascués, Pedro: «La arquitectura», en Navascués, Pedro y Quesada Martín, M. ${ }^{a}$ Jesús: El siglo xIX, bajo el signo del romanticismo, ed. Sílex, Madrid, 1992, pp. 11-134, pp. 129-130.

${ }^{24}$ Cfr. Rodríguez Romero, Eva: «Jardines de papel. La teoría y la tratadística del jardín en España durante el siglo XIX», Asclepio, 1999-I, pp. 129-158.

${ }^{25}$ Op. cit.

${ }^{26}$ Cortés y Morales, Balbino: Novísima guía del hortelano, jardinero y arbolista, Imp. del Colegio Nacional de Sordomudos y Ciegos, Madrid, 1885, pp. 192-211. Entre los invernáculos fríos o frigidarios distingue las típicas orangeries y los portales de jardín, que sirven para preservar del frío y las heladas a naranjos y otros árboles semejantes como granados y mirtos, bastando que se encuentren entre 4 y $5{ }^{\circ} \mathrm{C}$. Los invernáculos templados o estufas templadas para plantas algo más delicadas, deben alcanzar una temperatura de 8 a $10^{\circ} \mathrm{C}$. Las estufas propiamente dichas, o caldarios, son para las plantas de países cálidos y necesitan una temperatura de entre 15 y $30^{\circ} \mathrm{C}$. Para plantas tropicales o de climas templados las más recomendables son las llamadas «estufas holandesas» (como las que hay en Aranjuez y en la Alameda de Osuna), de cubiertas curvilíneas y construidas en hierro y cristal.

${ }^{27}$ Penelope Hobhouse: Plants in Garden History, op. cit., p. 231. Sobre el tema de los nuevos materiales en España ver, para una idea general, Sobrino Simal, Julián: Arquitectura industrial en España (1830-1990), Banco de Crédito Industrial, 1992. 
ca, ya que fusionaban los usos botánicos con los sociales, pues además de ser un lugar de aclimatación de plantas se convirtieron en el escenario de fiestas y reuniones ${ }^{28}$, símbolos del refinamiento y de la distinción. En este sentido podemos entender los proyectos realizados para rematar la terraza de la «Casa de la Reina», pero con la particularidad de que en España la tipología menos abundante fue precisamente la de las estufas construidas en el tejado, lo que los hace todavía más interesantes.

\section{Los proyectos para la «Casa de la Reina»}

Patrimonio Real poseía en Madrid, en el siglo XIX, muchos inmuebles que normalmente se alquilaban o se destinaban a algún uso productivo, como fueron la casa del Nuevo Rezado, la Real Fábrica de Tapices, la casa de Heros en la calle de Alcalá, la casa de los niños cantores en la calle de Leganitos, la Botica Real, la casa nueva de Pajes y la casa de la Ballestería, así como casas en la calle de la Palma Alta, la calle Preciados y la casa del Duende ${ }^{29}$. La llamada «casa de la Reina» no era exactamente del Patrimonio Real, sino propiedad particular de la reina Isabel II, por habérsela regalado el caballero don Alejandro Soler, niño expósito encontrado en la puerta de los duques de San Fernando y criado por éstos. El inmueble se encontraba en la esquina formada por la calle del Arenal, la Costanilla de los Ángeles n. 2 y la callejuela de Santa Catalina de los Donados (o calle de la Priora) ${ }^{30}$, una zona donde desde el siglo Xvi se alzaron las casas de familias nobles, como la de Lagarda, la los duques de Nájera, la de Juan de Córdoba y Celenque, el palacio de los duques de Arcos, el de Gaviria, la casa del duque de Fuentes, etc. ${ }^{31}$. En el Archivo de Palacio se conserva abundante documentación gráfica sobre este edificio, ya que Alejandro Soler encargó, en 1853, varias reformas internas al arquitecto Leopoldo Z. López y, en 1878, el proyecto de un invernadero que había de levantarse en lo alto del edificio, que fue realizado por el arquitecto-paisajista Pierre Quénat, de Paris ${ }^{32}$.

Se trataba del típico inmueble isabelino de viviendas, con establecimientos comerciales en los bajos (fig. 1 y 2), entresuelo más tres plantas de altura, rematado en una azotea en la cual había una carbonera. En la planta baja había numerosas tiendas, cocheras, cuadras, la vivienda del portero y una zona de servicio con cocinas ${ }^{33}$. La fachada era sencilla, con huecos alargados dispuestos regularmente, más altos los de la planta baja, rematados en arco rebajado éstos

${ }^{28}$ En revistas de la época, como La Ilustración Española y Americana, se solían dar reseñas sobre fiestas y eventos acontecidos en los invernaderos de los palacetes de la nobleza y la burguesía. Las nuevas costumbres sociales por un lado y también el nuevo valor otorgado a la vida privada por otro, modificaron por completo la arquitectura doméstica. En las nuevas casas y palacetes urbanos se distinguirán tres zonas: la privada (dormitorios, cuartos de aseo, roperos y antecámaras), la de servicios (cocina, lavadero, despensa, cuartos de sirvientes) y la pública (vestíbulo, salones, comedor, salas de juego y de fumar, despacho...). (Cfr. Simó, Trinidad: «Formación del espacio burgués», Fragmentos, n. ${ }^{\circ}$ 15-16, 1989, pp. 98-105). Las estancias que constituían esta zona pública solían dar a la fachada principal y estar comunicadas entre sí por puertas dispuestas a lo largo de un eje, para poder generar un gran espacio único durante las fiestas y recepciones ofrecidas por los señores. Los invernaderos y estufas estaban casi siempre en prolongación de estos espacios, a modo de transición al jardín, o bien en la azotea o patio interior de la última planta, para recibir luz natural. Fueron frecuentemente escenario de las fiestas, cumpliendo la misma función que los salones de la casa.

${ }_{29}$ José Luis Sancho: La arquitectura de los Sitios Reales, Patrimonio Nacional, Madrid, 1995, pp. 142-143.

${ }^{30}$ Quizás podría ser la casa (Costanilla de los Ángeles $n .^{\circ} 3 \mathrm{c} / \mathrm{v}$ calle de la Priora) donde, según Peñasco y Cambronero, se expuso al público el cadáver del infante D. Enrique, muerto en un duelo por el duque de Montpensier (Hilario Peñasco de la Fuente y Carlos Cambronero: Las calles de Madrid, Madrid, 1889, pp. 62-64) o, si no la de enfrente.

${ }^{31}$ Pedro de Répide: Las calles de Madrid, Afrodisio Aguado, Madrid, 1971, p. 50.

${ }^{32}$ A.G.P., planos n. ${ }^{\circ} 2122$ a 2136,2154 y 4489, plantas y detalles constructivos y decorativos firmados por Leopoldo Z. López en 1853; y planos $n^{\circ} 2111$ a 2118 , proyecto de invernadero, firmado por «P. Quénat, architecte-paysagiste,... Paris» en 1878 .

${ }^{33}$ A.G.P., planos n. ${ }^{\circ} 2122$ a 2130 . Son las plantas del edificio, desde el sótano y atarjeas hasta el resto de las plantas. Están trazadas a lápiz, muy borrosas, por lo que reproducimos los más nítidos. Carecen de firma y fecha. 

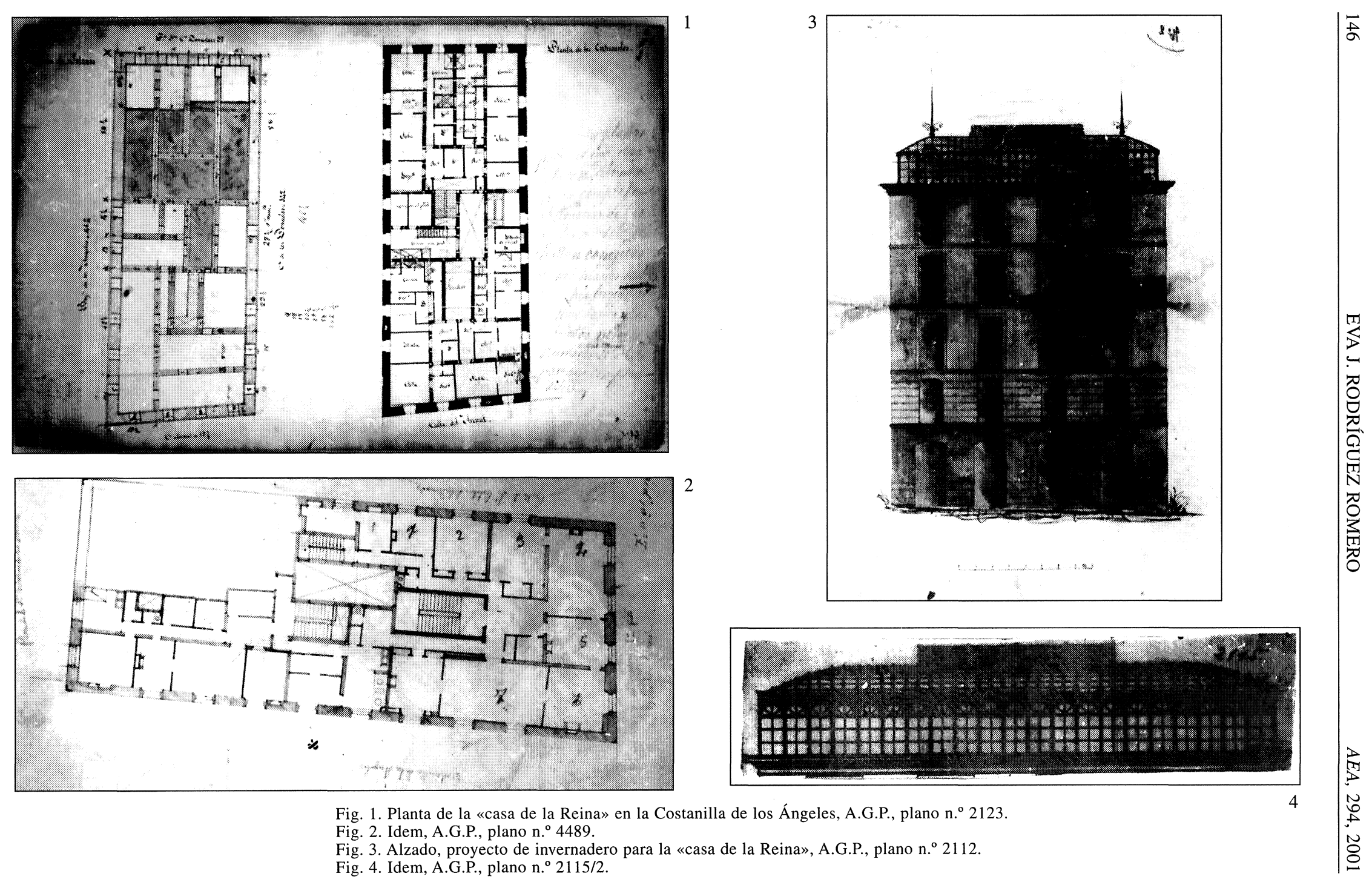
y los del entresuelo, y adintelados y enmarcados en molduras el resto. La separación entre pisos se marcaba con las típicas cornisas ${ }^{34}$, el paramento del bajo y el entresuelo se adornaba con un almohadillado fingido, de marcados tendeles horizontales, estando cubierto el resto con un revoco liso, excepto en la calle del Arenal donde la fachada se articulaba con pilastras ${ }^{35}$. El remate era una cornisa moldurada más marcada que las de separación entre plantas, sobre la cual habría de construirse el invernadero en hierro y cristal. En el interior, la decoración de las viviendas estaba muy cuidada y en uno de los pisos hubo incluso un baño con calefacción ${ }^{36}$, cuyo proyecto se elaboró también en Francia, como el del invernadero.

Veamos cómo era el proyecto para dicho invernadero. En realidad constaba de varias propuestas, aunque todas ellas eran variantes del mismo tipo, en hierro fundido decorado con filigranas y cristal, ocupando todo el esquinazo entre las tres calles a las que daba el inmueble y apoyado sobre el cornisamento del edificio. Desgraciadamente no hemos podido confirmar si se llegó o no a construir, pues el inmueble no se conserva en la actualidad. La primera propuesta (fig. 3) era una serre de nave rectangular, cubierta a cuatro aguas, de la que sobresalían cuatro buhardillas alineadas en vertical con los huecos de fachada de la casa. Toda la estructura, tanto de los paramentos como de la cubierta del invernadero, era metálica, con bastidores para pequeños vidrios cuadrados. Estaba decorada la línea de cornisa con guardamalletas caladas, el remate de los vanos destacados, así como el centro de la cubierta y los extremos de la cumbrera, con espigones de hierro forjado.

La segunda propuesta (figs. 4 y 5) constaba de dos planos, uno de ellos delineado a tinta y otro un grabado. El primero seguía un esquema más sencillo que el de la propuesta anterior, con el alzado totalmente homogéneo articulado en vanos de medio punto, con las enjutas caladas. La cubierta era igualmente a cuatro aguas, transparente, de vidrio sobre bastidores reticulados de hierro. En el centro de la misma se alzaba una barandilla decorada con volutas y filigranas metálicas. El grabado que acompañaba a este plano, aunque está clasificado con la misma autoría ${ }^{37}$ que el resto de los dibujos de esta estufa de tejado, es en realidad una lámina de la revista inglesa The Garden (fig. 6), que Quénat remitiría a modo de ejemplo. Se trataba de una «rooftop greenhouse» construida por Barn y Sugden sobre una casa en King Street, en el barrio londinense de Covent Garden en $1874{ }^{38}$.

La propuesta definitiva (fig. 7) se parece más a la primera de todas, aunque más decorada. Con cuatro buhardillas que avanzan sobre el frente del invernadero, rematadas ahora en arco de medio punto. Es muy curioso el despiece de los bastidores de los entrepaños, con pequeños rombos en las intersecciones entre los barrotes que forman la retícula acristalada. El arranque y coronación de estos entrepaños se adornan con flores. La separación entre el paramento y la cubierta del invernadero, así como la cumbrera, tienen una crestería calada y unos espigones en las esquinas, todo ello en hierro. En el centro de la cubierta se eleva una barandilla que nos hace pensar que en el interior habría una escalera para acceder a una pequeña terraza abierta en la zona central de la estufa.

Aunque en España, como hemos visto, también se proyectaban y construían invernaderos de diversos tipos, fue muy habitual encargar el diseño de los mismos y la elaboración de las

${ }^{34}$ A.G.P., planos n. ${ }^{\circ}$ 2131-2133-2135. Son detalles de las impostas que dan a la calle del Arenal, perfiles de cornisas y pilastras para la fachada. Firmadas por Leopoldo Z. López y fechadas desde abril a mayo de 1858 .

${ }^{35}$ A.G.P., planos n. ${ }^{\circ} 2132$. Idem. El plano n. ${ }^{\circ} 2136$ representa una granadilla para unas ventanas circulares y oblongas en la fachada de la calle del Arenal.

${ }^{36}$ A.G.P., plano $n .^{\circ} 2154$. Proyecto de calefacción para baño, para «M. Soler á Madrid».

${ }^{37}$ El arquitecto-paisajista Pierre Quénat, residente en la calle de Passy n. ${ }^{\circ}$ 10, París. Fue contratado en 1878 por D. Alejandro Soler, la persona que había regalado la casa a la reina y que seguramente se quedaría a su cuidado a partir de 1868.

${ }^{38}$ Fue publicada en The Garden, abril de 1875. Citada por John Hix: The Glasshouses, op. cit., p. 94. 

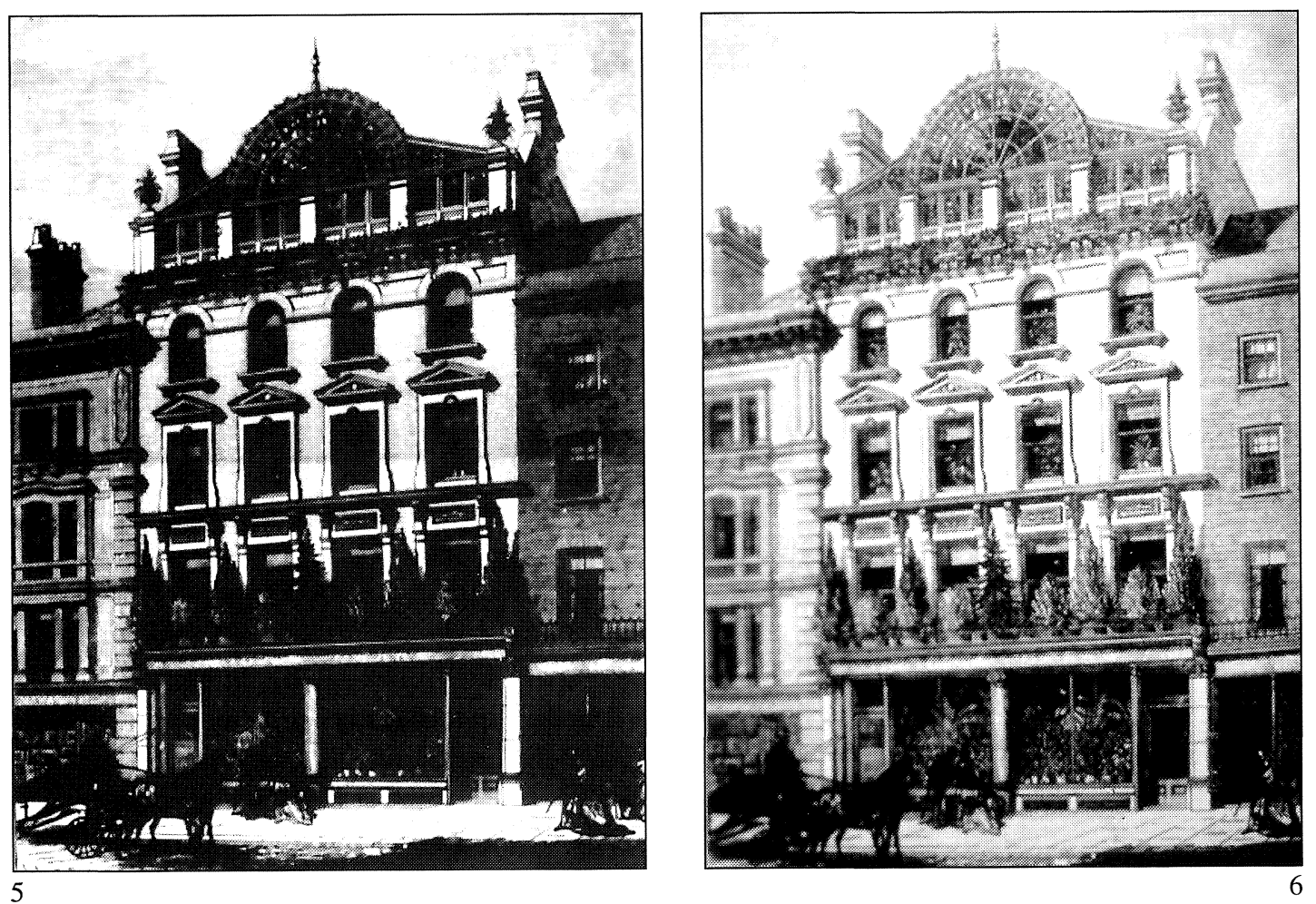

5
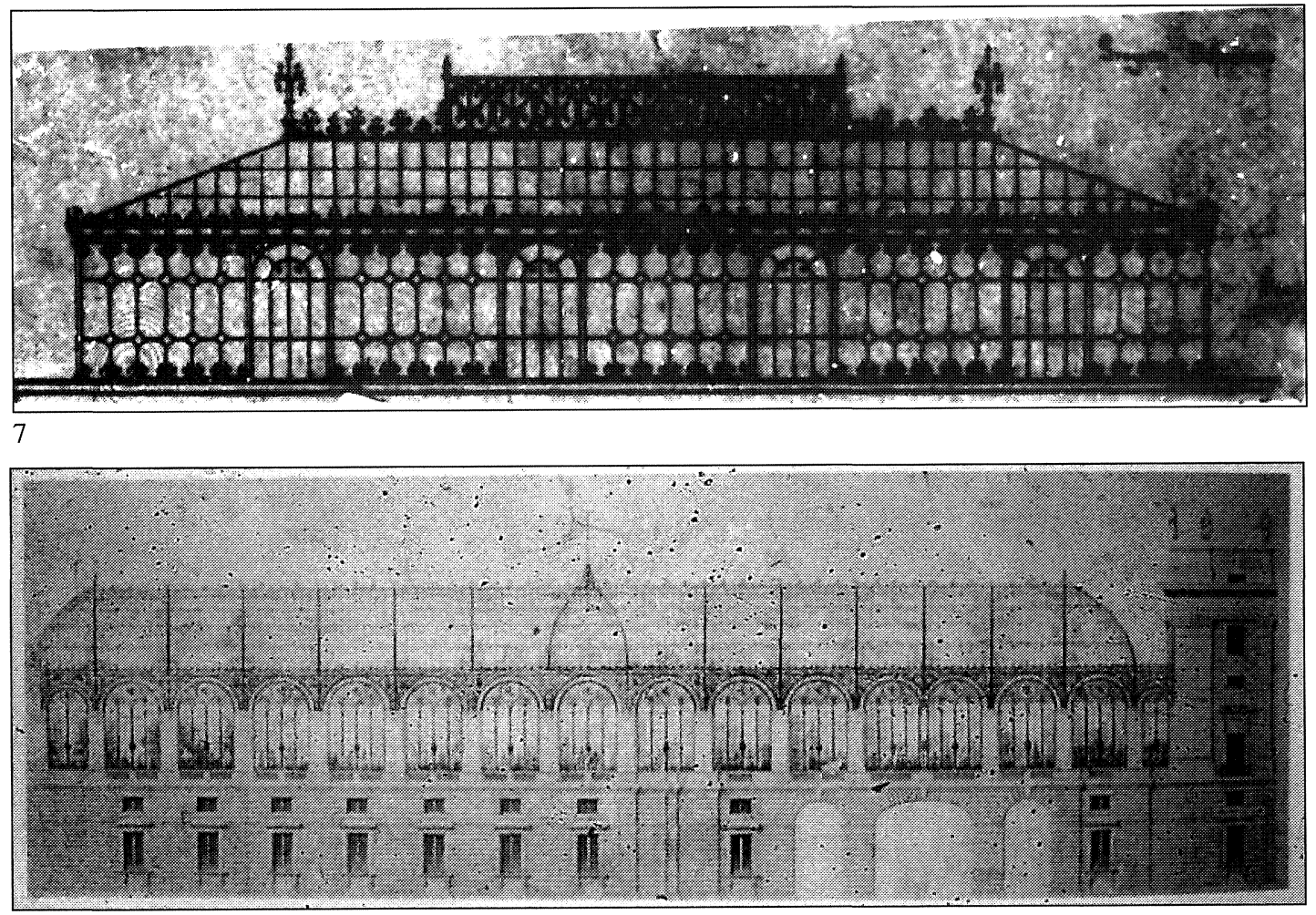

Fig. 5. Idem, A.G.P., plano n. ${ }^{\circ} 2115 / 1$

Fig. 6. Ilustración de The Garden, abril 1875.

Fig. 7. Proyecto de invernadero para la «casa de la Reina», propuesta definitiva, A.G.P., plano n. 2116

Fig. 8. A.G.P., plano n. 5952. 
piezas metálicas prefabricadas a Francia o Inglaterra, países en los que los progresos tecnológicos eran mucho más significativos que en el nuestro. En Francia tenían gran prestigio las Escuelas técnicas, sobre todo con la institución de la École Polytechnique, fundada en París en 1795, ejemplo que fue imitado en otros países europeos ${ }^{39}$. En Inglaterra durante el siglo XIX era habitual la producción en serie de algunos elementos de construcción, como vigas y columnas de hierro fundido, y además fueron frecuentes las intervenciones experimentales de los arquitectos en el campo de la ingeniería y viceversa. Por tanto, era lógico que los profesionales franceses o ingleses estuvieran más preparados para diseñar y construir invernaderos con todos los avances técnicos necesarios y que las personas pudientes de la época en España encargasen los proyectos de este tipo a extranjeros. Fue famoso en toda Europa, por ejemplo, el salon d'hiver de la princesa Matilde en París, descrito en la literatura de la época por Maupassant o Proust y, como en otros aspectos, la alta burguesía madrileña imitaría las formas de vida y la arquitectura de su homóloga parisina.

Semejantes a este invernadero de la «casa de la Reina» habrían sido, por ejemplo, la estufa del palacio de la condesa de Montijo, que aunque realizado en estructura de hierro era de estilo neoárabe, con columnas nazaritas sobre las que se elevaba una bóveda acristalada o el invernadero de la planta alta del Palacio de Linares y el del palacio Heredia-Spinola, que aún se conservan. También habría estado en la línea el «Jardín colgado» que Aníbal Álvarez proyectara para la galería del este de la Plaza de la Armería del Palacio Real (fig. 8) a finales de siglo ${ }^{40}$. A pesar de su monumental escala, parece haber sido concebido para el disfrute cotidiano de la familia real más que para fiestas, ya que ocupa la terraza inmediata a las habitaciones privadas de los monarcas. Aunque hubiese supuesto un gran contraste con la fábrica dieciochesca del palacio, habría supuesto un elemento de relación y apertura del mismo hacia la ciudad.

Pero estas estufas de tejado tienen más sentido en ciudades con climas más suaves que Madrid, donde en verano resultaría realmente complicado conseguir que las plantas no muriesen por un «exceso de calor» bajo su techo de cristal. Quizás se podían haber construido, en vez de invernaderos, umbráculos ventilados como los levantinos, pero no habrían sido protección suficiente en los fríos inviernos. Quizás por ello estos invernaderos en las cubiertas de los edificios de viviendas fueron abundantes en ciudades como París, Londres, que tuvo muchísimos jardines de tejado ${ }^{41}$, Viena, donde se encuentra la Anker Haus que Otto Wagner constru-

${ }^{39}$ Después de París, se instituyeron escuelas técnicas para la formación de ingenieros en Praga (1806), Viena (1815), Inglaterra, Pavía (1803), Nápoles (1811) y Roma (1817). En España hay que esperar a la segunda mitad del xIX para que aparezcan las primeras escuelas técnicas, entre ellas la Escuela de Arquitectura, que se separa de la Academia de Bellas Artes para impartir una formación más acorde con los nuevos tiempos. Se comienzan así a impartir asignaturas como historia de la arquitectura, construcción, estructuras, etc. En Francia se dio la conocida polémica entre ingenieros y arquitectos, pero en Inglaterra la preparación institucional era menos rígida y la colaboración de ambas profesiones era frecuente. Así fue común, por ejemplo, la decoración clásica unida a las grandes estructuras de hierro, concebida para elevar la calidad de la obra y darle más dignidad y representatividad. Las incertidumbres que provocaron el uso de los nuevos materiales «ingenieriles» en la arquitectura fueron superadas con las grandes obras en hierro de la segunda mitad del siglo XIX, bien de arquitectos, bien de ingenieros e incluso de jardineros (Paxton, Horeau, Eiffel, Dutert, Contamin, Labrouste...), creando estructuras que antes resultaban inconcebibles y liberándose de la subordinación a la presencia del «maquillaje» externo de los estilos. Aparecen edificios que logran expresiones estéticas completamente nuevas, que incitan la imaginación de sus coetáneos y sientan las premisas para un cambio cualitativo de los hábitos visuales y del gusto. (Ver p. ej. Sica, Paolo: Historia del urbanismo. El siglo XVIII, Insto. de Estudios de la Admon. Local, Madrid, 1992, cap. «Los progresos de las técnicas constructivas y las relaciones entre ingeniería y arquitectura», pp. 396-399 y Benévolo, Leonardo: Historia de la arquitectura moderna, G.G., Barcelona, 1987 (1 ${ }^{\mathrm{a}} \mathrm{ed}$. 1974), caps. «Revolución industrial y arquitectura (1760-1830)», pp. 11-60 y «Ingeniería y arquitectura en la segunda mitad del siglo XIX (1870-1890)», pp. 125-156).

${ }^{40}$ A.G.P., plano n. ${ }^{\circ}$ 5952. Cfr. Plaza, F. J. de la: Investigaciones sobre el Palacio Real nuevo de Madrid, Valladolid, 1975, lam. XLVI-2; Sancho, J. L.: «La imagen alfonsina del Palacio Real de Madrid», Espacio, tiempo y forma, serie VII, 1990, pp. 365-392; y VV.AA.: Las propuestas para un Madrid soñado: de Teixeira a Castro, Ayto. de Madrid, 1992 , p. 289.

41 Ver Hix, J.: op. cit., pp 93-96. 


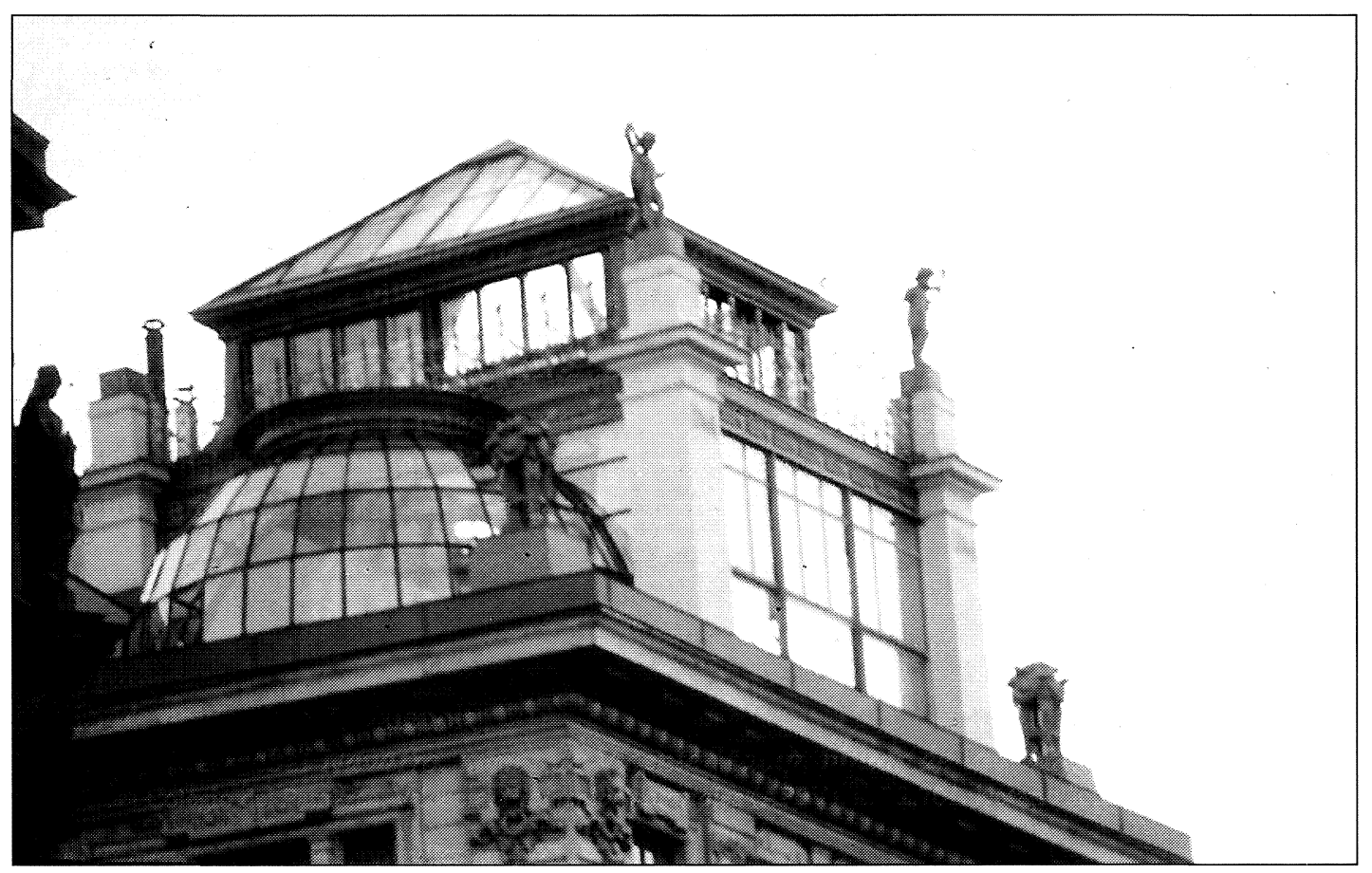

9

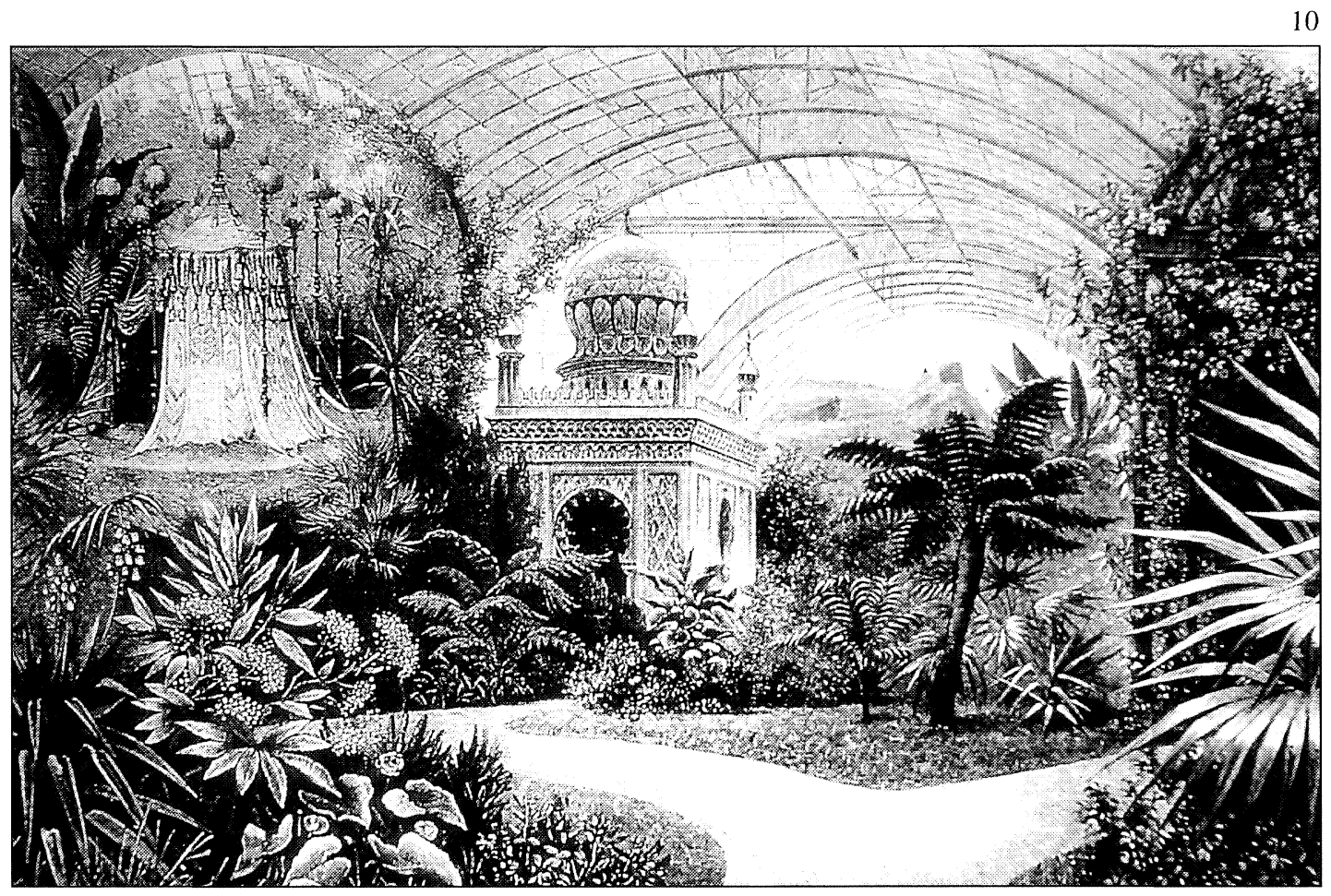

Fig. 9. Anker House, Otto Wagner, 1895.

Fig. 10. Jardín de invierno para el tejado en el palacio de Luis II en Munich, 1867 
yó en 1895 y que remata en una preciosa y elegante estufa (fig. 9) o Munich, donde Voit y Effner realizaron para Luis II un impresionante jardín de invierno de tejado ${ }^{42}$ en 1867 (fig. 10). Además, en esas ciudades era habitual aprovechar el espacio bajo cubierta para vivienda (con las famosas mansardas), lo que en Madrid resultaba imposible con los medios tradicionales de construcción de cubiertas. Aquí, aunque también estuvieron de moda las mansardas, abundaron los remates de edificios con acroterios al modo italiano, o con azoteas transitables, más acordes con el clima local.

De todas formas, queremos en estas líneas recordar la importancia que esta tipología edificatoria, los invernaderos y estufas, tiene desde el punto de vista de la historia de la jardinería y de la historia de la arquitectura, como canal de las nuevas técnicas y materiales, así como laboratorio de formas, por lo que instamos a la recuperación y valoración de nuestras estufas e invernaderos, que, por otra parte, son un tema prácticamente inédito en nuestra literatura artística y arquitectónica.

${ }^{42}$ John Hix: The Glasshouses, op. cit., p. 94. 